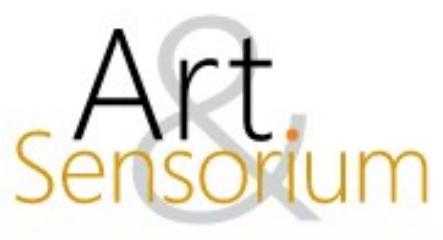

\title{
CULTURA ESTÉTICA E RELIGIOSIDADE NO IMPÉRIO PORTUGUÊ: OS ORATÓRIOS DOMÉSTICOS EM MINAS GERAIS NA ÉPOCA COLONIAL \\ https://doi.org/10.33871/23580437.2021.8.1.118-137
}

Alisson Eugênio ${ }^{1}$

\begin{abstract}
Resumo: Quando os portugueses colonizaram a América, eles trouxeram consigo suas devoções. Uma das formas de venerá-las foi a construção de um artefato, móvel de proporções variadas, destinado à vivencia devocional cotidiana conhecido como oratório. O objetivo deste artigo é observar os traços que definem, e os elementos que constituem, a sua forma, para compreender como ele expressa a cultura estética (isto é, os valores compartilhados que configuram as experiências sensoriais em relação ao que se convencionou a chamar de arte após o Romantismo) que predominaram na sociedade mineira colonial. Para isso, serão utilizados oratórios conservados no Museu do Oratório, localizado na cidade de Ouro Preto (antiga vila colonial, tombada pela Unesco como Patrimônio da Humanidade em 1980), os quais serão classificados, iconograficamente, de acordo com os critérios descritivos propostos por Erwin Panofsky.
\end{abstract}

Palavras-chave: Oratórios, religiosidade, cultura estética, Império português e Minas Gerais.

\section{AESTHETIC CULTURE AND RELIGIOSITY IN THE PORTUGUESE EMPIRE: THE DOMESTIC ORATORIES IN MINAS GERAIS IN THE COLONIAL PERIOD.}

\begin{abstract}
When the Portuguese colonized America, they brought with them their devotions. One of the ways to venerate them was the construction of an artifact, a mobile of various proportions, intended for daily devotional experience known as oratory. The objective of this article is to observe the defining traits and the elements that constitute its form in order to understand how it expresses the aesthetic culture (the shared values that configure the sensorial experiences in relation to what is conventionally called art after Romanticism) that predominated in colonial Minas Gerais society. For this purpose, we will use oratories preserved in the Museu do Oratório, located in the city of Ouro Preto (an old colonial town, declared a World Heritage Site by Unesco in 1980), which will be iconographically classified according to the descriptive criteria proposed by Erwin Panofsky.
\end{abstract}

Keywords: Oratories, religiosity, aesthetic culture, Portuguese Empire and Minas Gerais.

\footnotetext{
${ }^{1}$ Professor de história na Universidade Federal de Alfenas desde 2009. Graduado em História pela Universidade Federal de Ouro Preto (1996) mestre em História Social pela Universidade Federal do Rio de Janeiro (2000), doutor em história cultural pela Universidade de São Paulo (2008) e pós-doutor pela UFMG (2010). Autor de Fragmentos de liberdades: as festas religiosas das irmandades de escravos em Minas Gerais na época da Colônia (FAOP: 2007, E-papers: $2^{\mathrm{a}}$ ed. 2010), Reforming habits: the struggle against poor healt conditions in 19th Brazil (Verlag: 2010), Arautos do progresso: o ideário médico sobre saúde pública no Brasil na época do Império (Edusc:2012), Fontes para o estudo da história de Alfenas (Unifal-MG: 2013), Lágrimas de sangue: a saúde dos escravos no Brasil da época de Palmares à Abolição (Alameda: 2016) e Verso e reverso da modernidade: a modernização em Alfenas na Primeira República. Curitiba: Brazil Publishing, 2019 e As muitas faces de um gênio: tempo, vida e obra de Leonardo da Vinci. Alfenas: Universidade Federal de Alfenas, 2020. http://orcid.org/0000-0003-4294-2568. alissoneugenio@yahoo.com.br
} 


\section{CULTURA ESTÉTICA Y RELIGIOSIDAD EN EL IMPERIO PORTUGUÉS: LOS ORATORIOS DOMÉSTICOS EN MINAS GERAIS EN LA ÉPOCA COLONIAL}

Resumen: Cuando los portugueses colonizaron América, trajeron consigo sus devociones. Una de las formas de venerarlos era la construcción de un artefacto, móvil de variadas proporciones, destinado a la experiencia devocional diaria conocida como oratorio. El objetivo de este artículo es observar los trazos que definen, y los elementos que constituyen, su forma, para entender cómo expresa la cultura estética (es decir, los valores compartidos que configuran las experiencias sensoriales en relación con lo que se llama convencionalmente arte después del Romanticismo) que predominaba en la sociedad colonial de Minas Gerais. Para ello, se utilizarán los oratorios conservados en el Museu do Oratório, situado en la ciudad de Ouro Preto (antigua ciudad colonial, declarada Patrimonio de la Humanidad por la Unesco en 1980), que serán clasificados iconográficamente según los criterios descriptivos propuestos por Erwin Panofsky.

Palabras clave: Oratorios, religiosidad, cultura estética, Imperio portugués y Minas Gerais.

\section{Introdução}

Minas Gerais foi a capitania mais urbanizada da Província do Brasil do Império português. Sua formação decorreu da expansão da colonização do interior brasileiro. No final do século XVII, com a descoberta de metais preciosos em sua região, aos poucos uma corrente imigratória povoou seu território, dinamizando sua economia e gerando um mercado de consumo de bens além do trivial, como móveis mais sofisticados que necessitavam de artesãos habilidosos para sua produção.

Um destes móveis são os oratórios cuja estruturação, em formato retabular, é feita de madeira, em tamanho variado, com aspecto semelhante (conforme o tipo) ${ }^{2}$ a um armário, ou a uma prateleira, em cujo vão central (nicho) coloca-se uma estátua de um(a) santo(a), ou Cristo, ou de Maria, diante dos quais os devotos fazem suas orações e até celebram pequenos cultos (RODRIGUES, 2020 a, p. 353356; FERRERES, 1916, 9-11).

A elaboração deles seguiu os padrões da cultura estética dinamizada pelos dos estilos artísticos que se convencionou a chamar, com a consolidação do campo de estudos da história da arte, de Barroco e o Rococó, em voga na Europa (o primeiro no século XVII e o segundo no seguinte), que floresceram nas vilas coloniais mineiras no período, como mostram, entre outros, os estudos reunidos na obra organizada por Beatriz Coelho (2005). Uma delas, Vila Rica (atual Ouro Preto, cuja vista panorâmica é retratada na figura 1), ${ }^{3}$ apresenta um acervo tão rico, amplo e diversificado que mereceu em 1980 o título de Patrimônio Cultural da Humanidade da Unesco.

Uma das riquezas artísticas que constituem seu patrimônio cultural são os oratórios, cuja parcela considerável de exemplares está conservada no Museu do Oratório, de onde foram reproduzidas as imagens que servem de fonte deste estudo. ${ }^{4}$ Esse museu foi inaugurado em 1998 e abriga um acervo

\footnotetext{
${ }^{2}$ Sobre a tipologia dos oratórios, pode-se consultar o estudo de Maristane Carvalho Oliveira. Laços de fé: os oratórios mineiros do século XVIII. (Belo Horizonte, Monografia, Centro universitário de Belo Horizonte, 2009) 33-35, bem como a página https://museuregionaldesaojoaodelrei.museus.gov.br/oratorios-a-religiosidade-no-cotidiano.

${ }^{3}$ Essa vila surgiu da Bandeira de Antônio Dias de Oliveira, que, atraída pela descoberta de ouro nos seus arredores, chegou à sua região em 1696, e da consequente formação do arraial do Padre Faria sob a liderança do padre João de Faria Fialho e dos irmãos Camargos em 1698. Em 1711 esse arraial foi elevado ao status de vila, devido ao adensamento populacional que ali ocorreu impulsionado pela mineração aurífera, e em 1720, já como sede municipal, tornou-se capital da referida Capitania. Esse resumo foi feito com base em Vasconcelos, Diogo de. História antiga de Minas Gerais. $4^{\mathrm{a}}$ ed. (Belo Horizonte/Rio de Janeiro: Itatiaia, 1999).

${ }^{4}$ As imagens utilizadas neste artigo pertencem a uma instituição pública e estão disponíveis para acesso ao público na página web da instituição. Portanto, elas são de domínio público e, como tal, não necessita de autorização para sua
} 
de 162 peças, dos séculos XVII ao XX, caracterizadas pela diversidade de dimensões, estilos e tipos que permitem pesquisas diversas sobre a história religiosa e a cultura estética mineiras, particularmente do período colonial.

\section{Religiosidade e o impulso à produção de oratórios}

A cultura devocional praticada por meio de oratórios no catolicismo é resultante, no longo prazo, da propagação do culto aos entes e símbolos sagrados do cristianismo, principalmente após a consolidação da Igreja Católica como instituição responsável pela organização e controle de tal religião.

Essa propagação acabou criando as condições para a popularização do referido culto, sobretudo de Cristo, Maria, dos santos e das santas, de forma que, durante a Idade Média, aos poucos, a estas entidades passou-se a atribuir funções diversas, além das espirituais, relacionadas aos problemas da vida cotidiana, como a busca de proteção pessoal e coletiva contra as mazelas sociais e as calamidades humanas, conforme explica Jean Verdon (2018, p. 195 e 209).

Com as vicissitudes do catolicismo, as quais ensejaram movimentos reformistas, a cúpula dessa vertente religiosa cristã buscou meios para reforçar a fé e as práticas devocionais dos seus fiéis, como a difusão de representações simbólicas, a partir de pinturas e esculturas, de suas devoções. Desse modo, conforme explica Silveli Russo (2014, p. 228), "no período da Contra-reforma, as imagens religiosas resplandecem como veículos do sagrado e catalizadores de experiências espirituais," principalmente após o Concilio de Trento ocorrido entre 1545 e 1563, que procurou estimulá-las como um dos suportes da religiosidade popular capaz de intermediar as relações entre os fiéis e suas devoções.

Assim, de acordo com François Lebrun (1989, p. 7) "ante os ataques dos protestantes e na linha das posições doutrinais e das decisões do concilio, a Igreja pós-tridentina tende a revalorizar determinadas formas de devoção coletiva," sendo uma delas o incentivo ao exercício da veneração e culto religioso no âmbito familiar, seja em pequenos grupos ou de modo individualizado.

Dessa forma, estava criada uma das condições necessárias e fundamentais para os oratórios tornaramse um artefato, de grande utilidade para a prática religiosa privada, ou doméstica, que se difundiu ao longo do período posterior às conclusões doutrinárias do Concilio de Trento.

A outra condição está ligada ao avanço da valorização do indivíduo, da privacidade e do espaço doméstico ocorrida sob os auspícios da Renascença. Segundo Philippe Ariès (1989, p. 7-10), tal avanço tem como ponto de partida o fim da época medieval, quando o indivíduo, enquadrado em solidariedades feudais e comunitárias, começa a se libertar desses quadros, na medida que o processo histórico inaugurador da modernidade criou as possibilidades para a valorização da individualidade e, consequentemente, de "novas formas de religião que se estabelecem nos séculos XVI e XVII," as quais desenvolveram "uma devoção interior _ sem excluir, muito pelo contrário, outras formas coletivas da vida paroquial_" praticada de modo mais intimista.

Em outras palavras, nos termos conclusivos de Lebrun, essas duas condições, "desempenharam um papel fundamental no desenvolvimento de uma devoção cada vez mais interiorizada," (1989, p. 111) o que favoreceu a emergência de uma religiosidade caracterizada por práticas de devoção privadas, ou domésticas, das quais os oratórios, nos países católicos, são uma das expressões que mais ganharam projeção como instrumento do exercício da fé.

Durante a colonização do Novo Mundo, eles foram disseminados pelos mais diversos territórios conquistados pelas nações fiéis ao catolicismo. No caso de Portugal, a Capitania de Minas Gerais foi

utilização em publicações, desde que sejam devidamente citadas com a referência ao acervo institucional do qual elas fazem parte.

R. Inter. Interdisc. Art\&Sensorium, Curitiba, v.8, n.1, p. 118 - 137 Jan.- Jun. 2021 
um dos espaços coloniais onde se tornaram mais populares, devido, além da propensão religiosa da sua população, grande parte originária da metrópole, à riqueza que nela circulava. Pois, esta estimulou a formação de um "mercado" cultural muito dinâmico que fizeram da entidade federativa brasileira originária de tal capitania o Estado com maior quantidade de lugares inscritos, principalmente erigidos sob a influência das estéticas barrocas e rococós, na lista de bens tombados pela Unesco como Patrimônio da Humanidade.

Por esses motivos, ela é um lugar privilegiado para o estudo proposto neste texto, no qual será observado como os oratórios expressam, não somente a cultura religiosa colonial, mas também a os valores predominantes da cultura estética do período histórico no qual foram produzidos. Assim, será mostrado que ao longo do século XVIII, na capitania mais rica do império colonial português, a iconografia daqueles obedeceu aos gostos estéticos orientados pelos estilos Barroco e Rococó.

\section{Metodologia}

Para isso, serão utilizados os critérios analíticos definidos por Panofsky (2001, p. 47 e 53) como iconografia, isto é, "um ramo da história da arte que trata do tema ou mensagem das obras," a partir dos quais é possível fazer "a descrição e classificação das imagens." Foram analisadas dezenas de peças que estão conservadas no Museu do Oratório em Ouro Preto (antiga vila colonial, na época denominada Vila Rica, que foi capital da Capitania de Minas Gerais), as quais estão disponíveis para visitação pública in loco ou em https://museudooratorio.org.br/grupo_oratorio/oratorios-popularesdomesticos/, bem como podem ser consultadas no livro de catálogos deste museu organizado por Angela Gutierrez (1999).

Dessas imagens foram selecionadas as que apresentam uma melhor qualidade estética e, sobretudo, melhor expressam os estilos artísticos vigentes no período histórico e no recorte geográfico desta pesquisa. Feita a escolha, procedeu-se a identificação das características iconográficas de cada uma delas, para classificá-las conforme os padrões formais que predominam em suas feições. ${ }^{5}$

Depois disso, elas foram reunidas em três grupos, de acordo com os seus atributos estéticos e suas marcas iconográficas: Barroco e Rococó. E ao final, foram utilizados mais dois exemplares para reforçar a uma de suas características mais marcantes: o ecletismo, ou a coexistência no mesmo oratório de valores artísticos estéticos de ambos os estilos acima referidos.

Para isso, elas foram comparadas entre si, para observar os traços que definem, e os elementos que constituem, a sua forma, a fim de compreender como elas expressam a cultura estética (isto é, os valores compartilhados que configuram as experiências sensoriais em relação ao que se convencionou a chamar de arte após o Romantismo) que predominaram no tempo e lugar nos quais foram produzidos.

\section{Os oratórios mineiros coloniais}

$\mathrm{Na}$ Antiguidade, em casas gregas e romanas, era muito comum segundo Fustel de Coulanges (2004, p. 18), a presença de altares destinados à veneração das entidades religiosas "pagãs os quais, à semelhança dos oratórios, são compostos por um nicho, isto é, uma abertura (vão) em um pedaço de madeira ou rocha, construídos para a colocação de uma estátua que se cultuava domesticamente.

\footnotetext{
${ }^{5}$ Durante esse procedimento constatou-se o problema da datação e autoria. As peças analisadas não apresentam nome do autor e a data, pois estavam associadas aos trabalhos manuais classificados como ofícios mecânicos. Assim, quem a produzia era considerado na melhor das hipóteses um artesão habilidoso e não artista. Por isso, não tinha a preocupação em se identificar e nem mesmo datar a sua produção. Esse problema, porém, não trouxe maior dificuldade para este estudo, porque os aspectos formais das peças são inconfundíveis e o exame do material (madeira, tinta, etc.) não deixa dúvida a respeito da época em que elas foram confeccionadas.
} 
Com a ascensão do cristianismo, sobretudo após a criação da Igreja Católica, seus adeptos adaptaram esses objetos às suas práticas devocionais, substituindo as imagens do "paganismo" pelas cristãs, conservando a sua função original, mas lhe conferindo novo significado para atender a uma nova religiosidade, conforme nos mostra Silveli Russo (2014, p. 39).

Durante a consolidação e expansão do catolicismo, esses objetos de devoção foram adquirindo formatos diversos conforme a época e a sociedade que os adotaram. Isso porque, como mostra Maria Roque (2004) ao longo do seu estudo, a estrutura e a forma dos altares passaram por um processo de transformações que culminaram nos padrões definidos pela Reforma Católica (também conhecida como Contrarreforma). Consequentemente, os demais instrumentos usados para o exercício da fé, como os oratórios, também foram afetados pelo mesmo processo.

Assim, de acordo com Lucas Rodrigues (2020 a, p.1), em Portugal eles foram originados "dos trípticos (pintura elaborada por três painéis, sendo um central e fixo e os demais laterais e móveis ligados ao primeiro por dobradiças.), utilizados na ornamentação das igrejas," tal como o abaixo reproduzido.

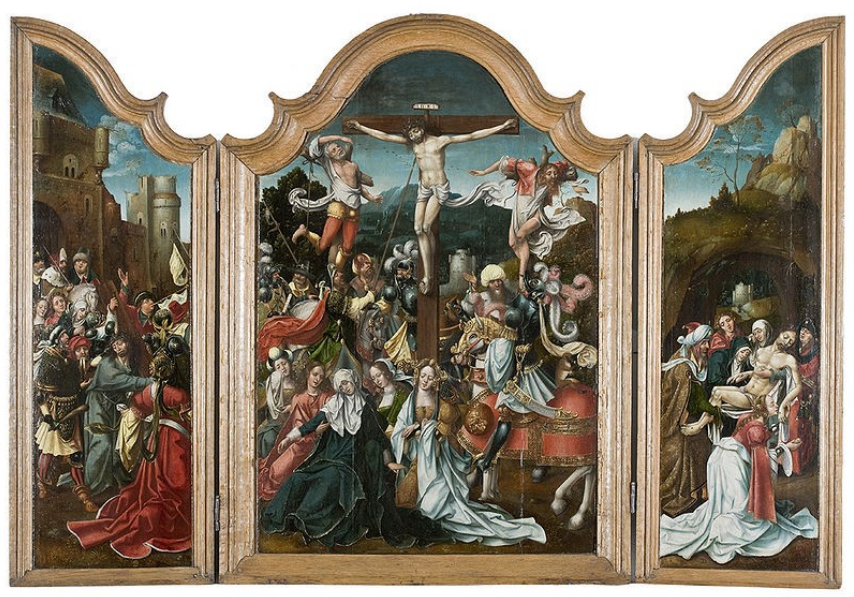

Figura 1. Fonte: Museu de Arte de São Paulo.

Obra Cristo carregando a cruz, a crucificação e o sepultamento (1520). Autor Jan van Dornicke.

A partir dessa composição, explica o mesmo autor, os oratórios foram aos poucos adquirindo "a forma de um pequeno armário," atingindo o formato como hoje são conhecidos no século XVII como resultado "da consagração e ênfase do culto aos santos, defendido pelo Concílio de Trento" (RODRIGUES, 2020 a, p.1) Dessa maneira, com avanço da colonização portuguesa, a cultura devocional materializada nesta espécie de mobiliário religioso é transplantada para a sua província americana, especialmente em Minas Gerais, onde ela encontrou terreno fértil para fincar suas raízes e consagrar-se como um símbolo da religiosidade popular.

Essa consagração foi possibilitada por pelo menos dois fatores. Um deles é o fato de que, em uma cultura religiosa, como a mineira, marcada pela assimilação popular de práticas devocionais diversas, compondo um conjunto multifacetado, como revelou Laura de Mello e Souza (1989, p. 88), a incorporação de novos objetos de culto espiritual, sobretudo quando ele não se chocava com as determinações eclesiásticas, não encontraria maiores resistências. $O$ outro é o fato de que em sociedades, como aqui estudada, caracterizada por grande apreço pelas imagens, pelo deleite dos olhos, pelo "embevecimento arrebatador e total dos sentidos," de acordo com a análise de Affonso Ávila (1994, p. 185), um elemento de considerável expressão ótica, como os oratórios, tende a ser absorvido com relativa facilidade desde que não colida com valores ou princípios que fundamentam a coletividade. 
Disto isso, segue a apresentação e classificação dos oratórios mineiros do século XVIII. Para classifica-los, é necessário sintetizar as características dos estilos que predominaram na cultura estética da Capitania de Minas Gerais no referido período histórico, para os leitores compreenderam a identificação de seus traços estéticos no mobiliário devocional em análise.

\section{A expressividade artística dos oratórios}

Comecemos pela escolha de uma definição de arte, sempre incompleta devido à complexidade deste fenômeno, a partir da contribuição de Umberto Eco (1971, p. 33), segundo o qual ela é "um modo de estruturar certo material," de lhe dar outra vida, ressignificando-o, com valor estético, a partir de um conjunto de fatores, tais como "personalidade do artista, a história, uma linguagem, uma tradição, um tema específico, uma hipótese formal, um mundo ideológico," etc.

Destes fatores interessa neste artigo a linguagem, quer dizer, a maneira de expressar ideias ou sentimentos por meio de traços constituidores de um conjunto simbólico compreensível por indivíduos de uma mesma comunidade, ou grupo, cultural.

Assim, pode-se falar de linguagem barroca e linguagem rococó, a partir das quais os que as empregavam, como em toda produção artística, buscavam comunicar valores, princípios, modos de ver, de viver, de pensar, de agir, enfim, de compreender e lidar com a vida e com o mundo.

A forma de linguagem a ser aqui investigada é a das artes visuais, plástica, composta por escultura e pintura, pois os oratórios são construídos com base em recortes de madeira compostos para a formação de uma estrutura semelhante a um armário, cujas laterais, fundo e portas (havia os que não as tinham e, quando é caso, assemelhavam-se a uma prateleira) são adornadas com pinturas, talhas, volutas, etc., e em cujo vão (nicho) se deposita uma estátua, conforme a figura abaixo.

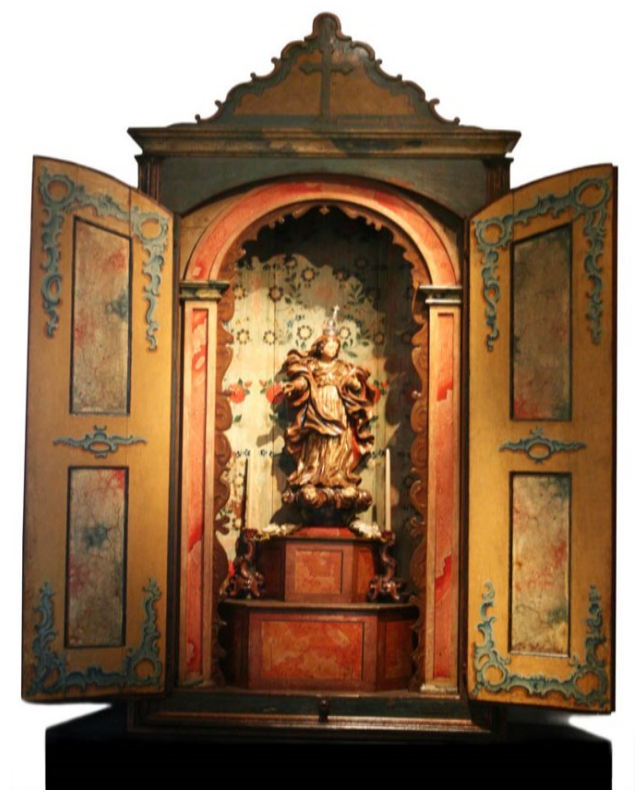

Figura 2. Fonte: Museu do Oratório: imagem MO 220.

Embora na época e no lugar focados nesta pesquisa estes artefatos não fossem vistos como arte, e a própria ideia de arte e a de artista não existissem no vocabulário e nem na cultura, conforme esclarece Guiomar de Grammont (2008, p. 24 - 25 e 225 - 226), mesmo assim, como conceito, pode-se aplicálas ao objeto deste estudo, pois o fato de as ideias não corresponderem com precisão àquele período histórico, isso não quer dizer que o fenômeno não existisse, sendo possível analisá-lo de acordo com 
as convenções interpretativas de nosso tempo e conferir a ele valor artístico. Afinal, conforme observa Angela Brandão (2009/2010, p. 42),

De um modo geral, o estudo do mobiliário europeu do século XVIII revela um momento de excelência. Os ateliês de fabricação de móveis de luxo, durante o século XVIII, atingiram um alto padrão de elegância e de perfeição técnica. A tipologia dos móveis ampliou-se quantitativamente, adaptados aos mais diversos usos, num processo de enriquecimento dos hábitos domésticos. ${ }^{6}$

Portanto, se os melhores, mais habilidosos, mais talentosos artesãos mineiros coloniais não eram reconhecidos como artistas e, consequentemente, seus trabalhos não fossem vistos como artísticos, no tempo de sua atuação, ainda assim as suas produções de melhor qualidade estética podem ser interpretadas como obras de arte de acordo com os critérios aceitos atualmente.

Seja como for, o que interessa neste trabalho é mostrar que os oratórios, como artefatos destinados à satisfação de uma demanda determinada pela dinâmica dos valores religiosos da sociedade para a qual foram produzidos, expressam a cultura estética sobre a qual foram estruturados os estilos Barroco e Rococó.

Para isso, do modo como metodologicamente este trabalho está organizado, é necessário partir da noção teórica de que, de acordo com Crifford Geertz (1978, p. 24) a cultura é um sistema, um conjunto de signos, a partir do qual o ser humano fundamenta seu modo de agir, pensar, de produzir, de sentir, enfim, de, viver.

Assim, a atividade artística, como uma prática cultural, é praticada com base em um conjunto de signos a partir dos quais seus praticantes expressam ideais e sentimento em relação à vida e ao mundo. Para a compreensão da operacionalização do modo como se pratica tal atividade, muito contribuirão alguns conceitos analíticos formulados por Pierre Bourdieu. Segundo ele, entre a prática (ação) e o meio social em que ela ocorre, existe um universo intermediário, denominado campo, "no qual estão inseridos os agentes e as instituições que produzem, reproduzem ou difundem a arte, a literatura e a ciência", entre outras formas de produção (BOURDIEU, 2004, p. 20). Isso quer dizer que todo praticante (agente) se fundamenta em um campo, que, além de ser um locus de mediação entre sua prática e o meio social no qual pratica, é também um microcosmo social que exerce influência decisiva na forma dos indivíduos nele inseridos ver o mundo e atuar nele. Para melhor explicar isso, Bourdieu (2001, p. 190) elaborou o conceito de habitus, isto é, "sistema das disposições socialmente constituídas que", na condição de um modo de operação dos campos, "constituem o princípio gerador e unificador do conjunto de práticas e das ideologias de um grupo de agentes."

Em outras palavras, o habitus é uma matriz que dinamiza as percepções e ações, uma vez que ele é resultante, em cada indivíduo, do processo de interiorização das regras, normas, valores e crenças (cultura) de uma dada sociedade, proporcionando ao campo a sua essência como espaço social ordenador e regulador das práticas (ações), que sendo dessa maneira ordenadas e reguladas conferem aos seus praticantes suas especificidades operacionais.

Embasado neste quadro teórico, pode-se dizer que os artífices responsáveis pela construção de oratórios, como demais produtores de outros campos de atuação, ao interiorizarem regras, normas, valores e crenças da sociedade na qual estavam inseridos, particularmente da cultura estética e da

\footnotetext{
${ }^{6}$ Além desse estudo, outros dois que ajudaram a orientar minha observação sobre o mobiliário mineiro do tempo da Colônia foram feitos por BRANDÃO, Ângela. Das pontes aos castiçais: a produção de mobiliário artístico em Minas Gerais do século XVIII e os ofícios mecânicos. In: Revista Científica, v. 4, n. 2, p. 50-66, 2009 e SMITH, Robert. Igrejas, casas e móveis. Aspectos da arte colonial brasileira. Recife: Universidade Federal de Pernambuco, 1979.
} 
religiosidade então predominantes, expressaram tal interiorização na produção da arte fazer seus artefatos.

Em outras palavras, eles estavam sintonizados com a linguagem artística de sua época e, com efeito, os oratórios por eles elaborados, parte deles conservados em instituições museológicas com o Museu de Ouro Preto, expressam os valores compartilhados que configuram as experiências sensoriais que davam vida, no meio social no qual atuavam, ao que se convencionou chamar de arte durante a consolidação da sociedade burguesa.

Isso quer dizer, portanto, que suas produções são resultado, entre outros fatores, da sintonia criativa de um dinâmico sistema cultural do qual fizeram parte e souberam se adaptar e se apropriar para o exercício de sus atividades artesanais.

\section{O Barroco}

Esse estilo começou na Itália ao longo da segunda metade do século XVI, atingindo sua plenitude no século seguinte, quando foi difundido no Ocidente e adaptado às características de cada sociedade que o adotou, até a ascensão do Rococó (MAINSTONE, 1980, p. 1). Sua emergência é resultado de uma situação histórica tensa cujas inquietações culminaram no que Paul Hazard (2015) chamou de crise da consciência europeia, isto é, a percepção de que as promessas do antropocentrismo renascentista ficaram inacabadas frustrando as esperanças de um futuro otimista.

Essa crise decorreu de uma série de acontecimentos históricos gerou uma apreensão inquietante no conjunto das sociedades do Antigo Regime. A euforia do crescimento econômico do século anterior, impulsionada pela expansão marítima, pela colonização e pelo incremento comercial em escala oceânica, cedeu lugar a uma longa estagnação e um conjunto de guerras religiosas e mercantis que disseminou penúria e favoreceu a disseminação de um sentimento de frustração de expectativas. As certezas a respeito do universo e do lugar por nosso planeta nele ocupado foram abaladas com descobertas científicas, as quais tiraram da Terra a sua centralidade e revelaram um universo muito maior e muito mais complexo do que até então se admitia. A euforia antropocêntrica, impulsionada pelo Renascimento, sofreu forte abalo pelos desdobramentos da Reforma (promovida inicialmente por Lutero e pulverizada por outros líderes religiosos nos quatro cantos da Europa) e pelo esforço contrarreformista do catolicismo. As convicções políticas, de uma sociedade que concebia o poder público como uma delegação divina ao soberano, foram estremecidas pela adaptação do conceito de revolução dos astros à vida social, concorrendo para criar as condições históricas favoráveis à construção de uma teoria política revolucionária colocada em prática vitoriosamente pela primeira vez na Revolução Inglesa.

Tudo isso, em um dinamismo temporal convergente no mesmo período histórico, produziu uma sensação de múltiplas inseguranças (científica, econômica, espiritual, política, entre outras), que segundo José Antonio Maravall (1997, p. 116), contribuiu "para criar o clima psicológico do qual surgiu o Barroco, e do qual se alimentou, inspirando seu desenvolvimento nos mais variados campos da cultura."

Esse clima psicológico, marcado por uma consciência em crise, gerou "homem barroco," um indivíduo, conforme definição de Rosário Villari (1995, p. 9), que abriga em si uma conflitualidade marcada por "comportamentos aparentemente incompatíveis ou nitidamente contraditórios," devido à sua tentativa de conciliar polos antagônicos que o fazia oscilar entre a euforia (expressada em suas festas) e a sua angústia (expressada em seu fervor religioso).

Ele se comportava dessa porque havia perdido a confiança, a esperança, nas palavras de Garcia Morejón (1968, p. 45), “el optimismio de la época precedente" e isso o conduziu, junto com os esforços da reforma tridentina, a uma tendência ascensional, de forma que, como argumenta, Helmut 
Hatzfeld (1966, p. 18), em sua forma de se exprimir "el destino final humano, el movimento desde el pasado al futuro a través del presente, el crescer de la muerte dentro de la vida, se hacen visibles."

Isso explica a inquietude, a tensão, a instabilidade, caracterizantes do caráter, da essência, do Barroco como um modo de expressão humana diante da vida e do mundo. Essas características, quando observadas nas artes plásticas pela ótica de Heinrich Wölfflin (2012), se revelam em uma forma definida por traços curvilíneos bem acentuados, colunas espiraladas e por cores fortes dispostas de maneira a produzir um contrastante profundo entre a luz e a escuridão, gerando um movimento muito agitado cuja intensidade superou enormemente aquele praticado, harmoniosamente, por Leonardo da Vinci.

Em Portugal, país marcado por uma religiosidade fortemente influenciada pelo ideário "contrarreformista", tal estilo encontrou terreno fértil para se disseminar, tendo atingido seu apogeu no reinado (1707 - 1750) de D. João V e se estendido ao seguinte, conforme mostram os historiadores portugueses, como António Felipe Pimentel (1993, p. 32). Por essa razão, na periodização das características da linguagem barroca do referido país, este período é denominado joanino.

Durante ele, diversas e grandiosas manifestações estéticas proliferaram pelo país, "sob os auspícios da produção aurífera brasileira" (PIMENTEL, 1993, p. 31) muitas delas apoiadas pelo patrocínio régio, como (no campo da arquitetura, por exemplo) o conjunto monástico do Menino Deus, a Biblioteca da Universidade de Coimbra e o Palácio de Mafra, o que levou os especialistas a considerar aquele período o momento de triunfo da sua cultura barroca (entre eles, TEIXEIRA, 1993).

$\mathrm{Na}$ Capitania de Minas Gerais, onde o Barroco chegou com os portugueses, os marcos predominantes da estrutura básica da sua religião oficial e da sua estética são em grande medida influenciados pelos colonizadores, motivo pelo qual, não obstante as suas peculiaridades, a cultura barroca vivenciada pelos seus habitantes e praticada pelos seus artífices é tributária, principalmente, do período joanino e das diversas tendências que o dinamizaram.

Nela, conforme mostra o estudo de Myrian de Oliveira e Adalgisa Campos (2010), foi na arte devocional que o Barroco melhor se exprimiu. Isso se deve a um conjunto de fatores, entre os quais se destaca a impactante força, ou o peso da influência, do catolicismo na cultura portuguesa. Tanto que, de acordo com Sérgio da Mata (2002, p. 20), grande parte da gênese do seu espaço urbano foi orientado pelas representações e práticas religiosas.

Em outros termos, trata-se de uma região onde a religião chegou antes do Estado, onde a construção de capelas, embriões de muitas de suas igrejas, foi a primeira preocupação dos colonos lá estabelecidos, onde os nomes escolhidos para se referir a uma localidade foram inspirados, em parte da sua composição, nas denominações de suas devoções. Vila Rica, por exemplo, cidade monumento rebatizada em 1823 como Ouro Preto, foi constituída como sede municipal a partir da junção do Arraial de Nossa Senhora do Pilar e o Arraial de Nossa Senhora da Conceição de Antônio Dias arraial.

Nessa sociedade assim caracterizada, os oratórios (um artefato especialmente produzido para o exercício cotidiano da fé) que doravante serão iconograficamente descritos, são um dos seus emblemas mais expressivos, por representarem um conjunto de práticas culturais que reúne um modo estético de produção e um modo religioso de devoção.

Tomemos como exemplo, de peças em que predominam as características barrocas, as figuras quatro e cinco, abaixo reproduzidas do Museu do Oratório sediado em Ouro Preto-MG, como as demais que lhe seguem. 


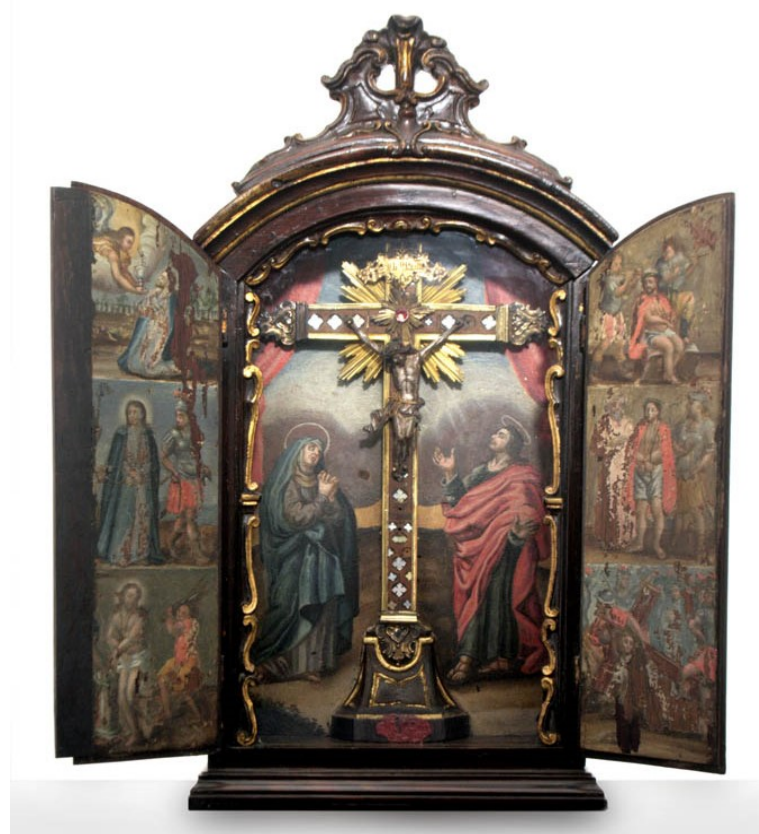

Figura 3. Fonte: Museu do Oratório: imagem MO 215.

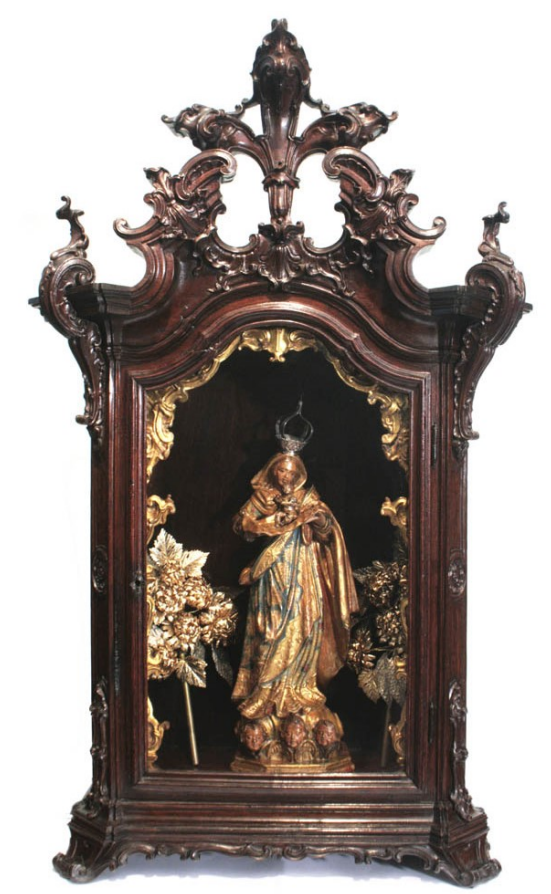

Figura 4. Fonte: Museu do Oratório: imagem MO 180.

Essas peças, como as demais que serão reproduzidas ao longo deste texto, foram produzidas aproximadamente entre meados do século XVIII e as décadas iniciais do século XIX; recorte cronológico no qual estão compreendidos o final do período joanino (1706-1750), o josefino (17501777) e o mariano (1777-1815).

Uma das características da cultura artística portuguesa praticada em tal recorte é o ecletismo, conforme mostra, entre outros autores, Paulo Varela Gomes (1988) ao longo de seu estudo. Consequentemente, oratórios dessa época, em sintonia com tal caracterização, apresentam normalmente traços iconográficos dos estilos então predominantes, embora um deles tenda a predominar na sua produção conforme o período no qual foram produzidos e as referências, as habilidades e o gosto de quem os produziu. 
Nas figuras acima percebe-se um conjunto estético marcado por cores fortes, estrutura robusta, curvas bem definidas, ornamentação com talhas e representação pictórica ao gosto da sensibilidade barroca.

Na primeira delas, destaca-se um conjunto cênico composto por pinturas de inspiração bíblica, cuja função é integrar-se com a peça central esculpida, para evocar os passos da paixão de Cristo, evidenciar o tema central da devoção, o martírio, e reforçar a sua centralidade cênica e devocional, expressando, desse modo, a dramaticidade típica da cultura barroca e sua visão trágica do mundo, a qual, como explica Helmut Hatzfeld (1966, p. 33), é resultado de uma época em que o artificial mundo platônico dos humanistas é substituído pelas renovadas indagações a respeito dos eternos e angustiantes problemas do homem, a começar pelo de sua salvação.

$\mathrm{Na}$ segunda delas, há nítidas inovações em relação à primeira (embora conserve a austeridade e solidez estrutural do período joanino, de acordo com a classificação de aplicada por Robert Smith (1979) em sua pesquisa). Nela a ornamentação é acrescida de entalhamento acentuado, de rocalhas, ainda que discretas, que indicam assimilação da linguagem rococó, e de elementos fitomórficos, tais como: palmeta, florões e acantos, os quais não cumprem função meramente decorativa, pois também visam enfatizar a representação da devoção esculpida e conferir a ela maior expressividade identitária que reforça a sua essência religiosa.

E essa é a tônica dos demais exemplares que serão expostos doravante, isto é, a presença, sobretudo na segunda figura, de características iconográficas de períodos e estilos diferentes, ora com predominância de um, ora de outro, de acordo com o momento da sua produção e com a experiência de quem os produziu.

\section{O Rococó}

Esse estilo, de origem francesa, começou a ser esboçado no final do século XVII e vigorou no reinado de Luís XV (1715-1774), quando foi disseminado pelo Ocidente, onde predominou até a consolidação do Neoclassicismo. Sua emergência é resultado das respostas, às tensões e inquietações provocadas pelas crises que abalaram a Europa durante o declínio da Renascença, que criaram as condições históricas das quais surgiram o movimento intelectual conhecido como Iluminismo (KIMBALL, 1949, p. 11).

Os expoentes, philosophes, de tal movimento construíram, como nos mostra Georges Gusdorf(1972), um ideário por meio do qual procuraram convencer a sociedade de que a construção de um mundo melhor é possível. Para isso elegeram a razão (aplicada aos mais diversos campos: arte, ciência, economia, educação, justiça, política, etc.) como um dos instrumentos fundamentais para a promoção do progresso humano rumo ao aperfeiçoamento civilizacional.

Isso porque, o instrumento até então predominantemente utilizado para solução dos problemas do mundo, a religião, não se mostrava suficientemente eficiente e, além disso, chegou-se à convicção de que o homem não podia mais, com as mãos erguidas para o Céu, esperar apenas de Deus o remédio para tantas calamidades, como explica Paul Hazard (1973, p. 7).

Agora, com o raiar das Luzes, suas mãos deveriam ser direcionadas para outra direção, para si mesmo, para a sua capacidade de, por meio do conhecimento racionalmente construído, ampliar o seu entendimento sobre a vida, em todos os seus aspectos (principalmente a natureza), para dela levantar o véu que esconde os seus segredos e torná-los proveitosos para a humanidade.

O movimento iluminista, assim caracterizado, recuperou o otimismo antropocêntrico renascentista e, baseado nele, construiu uma nova utopia, a utopia do progresso, a partir da qual seus próceres, ao difundi-la, esperavam eliminar as trevas que obscureciam a Terra e tolhiam a felicidade humana.

Nascido neste contexto histórico, o Rococó, como toda a forma de expressão estética, expressa os ideais de seu tempo; um tempo em que o hedonismo, como um ideal de vida fundamentado na busca 
do prazer, foi exacerbado. Por isso, ele foi considerado, talvez com um pouco de exagero, por Roger Laufer (1963) como um estilo das Luzes.

Como tal, seus aspectos formais são marcados: por cores claras, suaves, tênues, com uma certa predileção pelo dourado, azul-céu e verde-água (cores que simbolizam a prosperidade, a confiança, a harmonia) por curvas quebradas (como se quisessem expressar uma guinada brusca nos rumos da sociedade), rocalhas acentuadas e por um excesso decorativo, ornamental, com bastante utilização de motivos florais, tanto na pintura, quanto nas talhas, como descreve Philippe Minguet (1966).

Essa linguagem artística, derivada da dinâmica e da abertura a novas experiências do Barroco, começou a ganhar força e foi impulsionada em Portugal no reinado de D. José (1750 - 1777), período no qual ela conviveu com a que lhe originou, conservando o mesmo caráter esplendoroso do reinado anterior graças à riqueza gerada pelos metais preciosos de Minas Gerais, de onde, além do ouro já por essa época em retração, agora vinham abundante quantidade de diamantes.

Na Capitania de Minas Gerais, como mostra Myrian de Oliveira (2003) o rococó também foi assimilado pelo gosto de parte das elites afinadas com as tendências estética europeias, particularmente de Portugal de onde continuavam vindo para tal capitania levas e levas de colonos, com uma sensibilidade visual impregnada dos valores culturais de suas origens. Assim, enquanto na França, em uma sociedade que se laicizava aceleradamente, tal estilo, no plano ideológico, é resultado de transformações fundamentais, particularmente no modo de pensar, e por isso menos afeita ao ideário doutrinário do catolicismo (embora não tivesse deixado de expressar a fé dos franceses), naquela capitania as bases em que ele foi sustentado foi outra, como a mesma autora argumenta em outro estudo:

Diferentemente do tempo de duração significativa (quase um século), que condicionou na Europa a substituição do barroco italiano pelo rococó francês, trazendo em seu bojo o rastro do Iluminismo e do hedonismo epicurista que caracterizaram o setecentos francês, na Colônia a transição operou-se em menos de vinte anos, entre as décadas de 1750, que assinala a fase final do barroco joanino na capela mor do Pilar de Ouro Preto por exemplo, e a de 1770, quando surge o primeiro interior rococó plenamente caracterizado, o do Santuário de Matosinhos em Congonhas. Neste curto espaço de tempo a sociedade e a cultura mineiras não sofreram modificações substanciais, especialmente no campo da religião, no qual as mudanças são sempre mais difíceis de assimilar. Em consequência, a cultura religiosa que engendrou o barroco em Minas Gerais, foi a mesma que engendrou o rococó, continuando a prevalecer na segunda metade do século XVIII o mesmo clima de espiritualidade de fonte contra-reformista, em seus aspectos aparatosos nos rituais do culto católico (OLIVEIRA, 2004, p. 2).

Desse modo, o Rococó mineiro, como em outras sociedades que continuaram muito apegadas ao espírito religioso insuflado pela reforma tridentina, continuou a ser praticado como uma forma de expressão acentuada da intensa religiosidade popular, o que, na essência, o aproxima do Barroco do qual ele foi originado. 


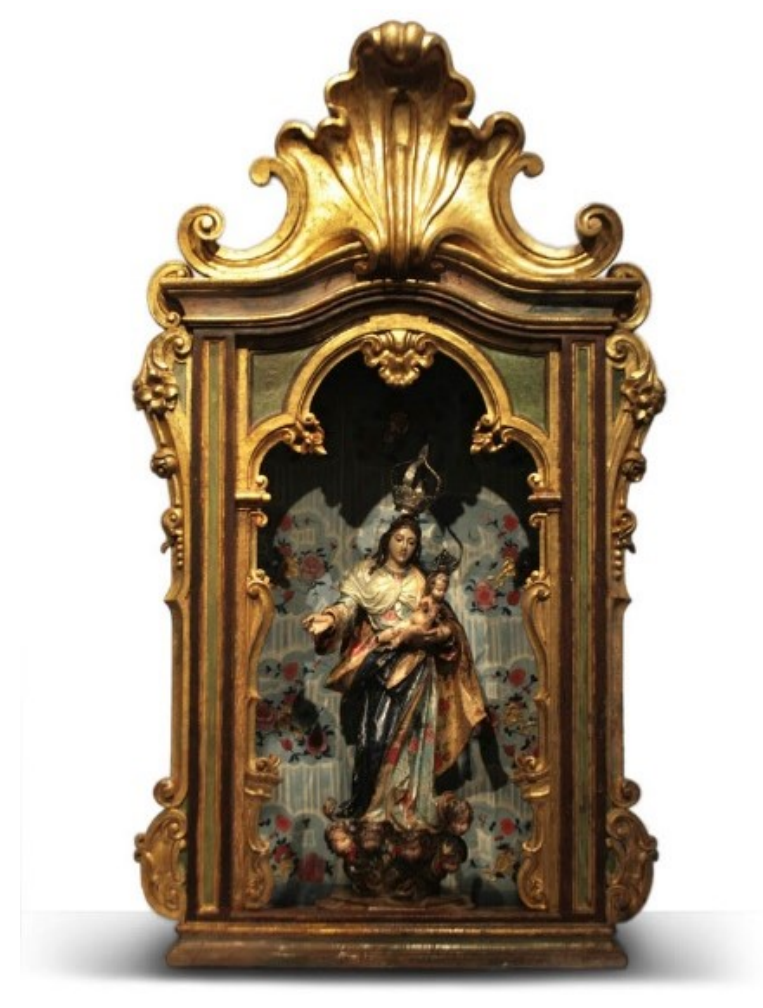

Figura 5. Fonte: Museu do Oratório: imagem MO 180.

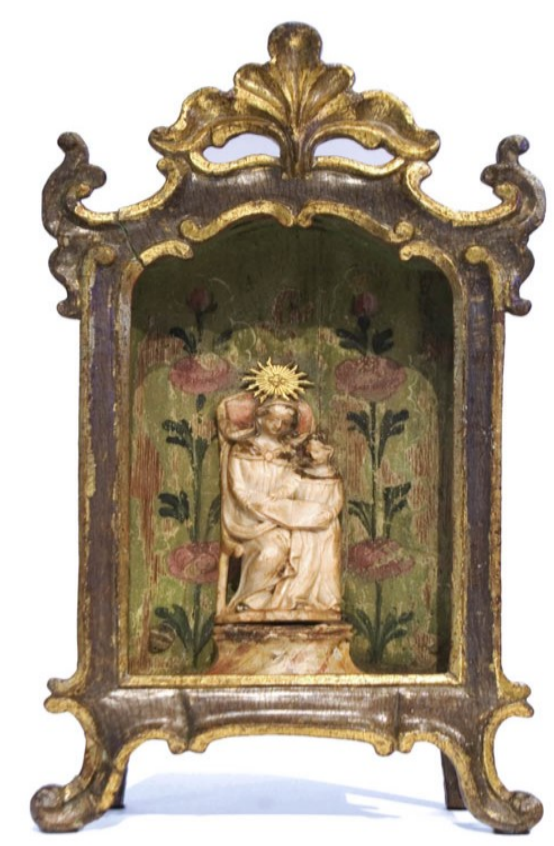

Figura 6. Fonte: Museu do Oratório: imagem MO 198.

As figuras acima apresentam um conjunto iconográfico cujos traços predominantes revelam uma elaboração nitidamente influenciada pela linguagem rococó, principalmente na ornamentação, em que se destaca a cor dourada, com a presença de talhas e palmetas, mais expressivas na primeira delas, volutas, rocalhas, concheados destacados, com pinturas ao fundo da estrutura retabular com motivos florais e em cores mais suaves (a primeira azul claro e a segunda verde claro) que remetem ao estilo predominante na época de D. José. 
Em relação à composição pictórica, a presença de rosas, vermelhas na primeira e cor-de-rosa na segunda, evoca forte apelo bucólico e sua marcante afeição pelas paisagens naturais que expressam um ideal de certa simplicidade, quase ingenuidade, diante da vida. Além disso, mais do que simples função decorativa, essas flores, além de conferir maior destaque ao elemento devocional esculpido ao centro, também reforçam a identidade da devoção mariana nele representado, uma vez que a rosa também simboliza Nossa Senhora em suas diversas versões, conforme apurou Lucas Rodrigues (2020 b, p. 365) no Tratado das significaçoens das plantas, flores, e frutos, que se referem na Sagrada Escrittura: tiradas de divinas, e humanas letras, com suas breves considerações pelo Padre Fr. Isidoro de Barreyra, editado em 1698.

\section{Ecletismo}

Os estilos artísticos, como tudo derivado da ação humana, se transformam ao longo do tempo. E por que (?) isso acontece ainda não foi satisfatoriamente respondido. Todavia, há alguns fatores que devem ser levados em conta para a compreensão da arte de uma época e sociedade, sendo um dos mais importantes o contexto no qual ela é produzida. Neste sentido, para Arnold Hauser (1997, p. 36), a dialética das relações sociais, ao dinamizar a vida humana, cria condições para os artistas buscarem novas formas de expressão estética, o que explicaria a transição de uma linguagem artística a outra.

Mas isso não quer dizer que o modo de fazer a arte dependa apenas do contexto da sua produção, pois para uma mudança de padrão estético ocorrer, também é necessário, segundo os teóricos da visibilidade pura, como Heinrich Wölfflin (1982), que os artistas tenham atingindo o auge de suas possibilidades criativas dentro do estilo preponderante, que ao ser esgotado vai abrindo caminho para novas experiências formais.

Em outras palavras, a transição de uma linguagem artística para outra depende da interação entre diversos fatores e, enquanto ela não for consolidada, enquanto a anterior ainda não esgotar suas possibilidades criadoras, enquanto ambas coexistiram, elas continuam servindo como referência para os produtores elaborarem seus trabalhos, e muitas vezes, como a nova forma de fazer nasce da dinâmica da anterior, elas se confundem na mesma "criação" e, não raro, mesmo depois da consolidação a posterior conserva elementos da que lhe antecedeu.

Em relação aos estilos em estudo, por exemplo, o Rococó apresenta tantas características do Barroco ao ponto de, até ele ser definitivamente reconhecido como uma linguagem autônoma no final dos anos 1960, grandes teóricos, como Heinrich Wölfflin, o interpretavam como uma variação, ou nuance, barroca (THOMAS, 2004, p. 1-2).

Essa permanência do Barroco no Rococó pode ser compreendida, de acordo com Rodrigo Baeta (2012, p. 208), pelo fato de que essas linguagens estéticas permitiram "que a expressão artística alçasse voos infinitamente mais altos," ao suscitar a "ruptura com qualquer preconceito relativo ao uso de composições e espaços, abrindo o caminho para uma espécie de ecletismo que acolheria, em uma mesma obra, soluções vinculadas a outros momentos da história da arte."

E é isso, entre outras coisas, que mostra Paulo Varela Gomes (1988) ao longo do seu estudo sobre a cultura artística em Portugal no século XVIII, para quem uma das marcas da produção estética em tal lugar e tempo é o ecletismo que se pode observar em todas as modalidades de produção estéticas, particularmente na arquitetura, escultura e pintura.

No caso do recorte espacial em estudo neste artigo, originado da colonização portuguesa e por isso influenciado pelas tendências artísticas em vigor na Metrópole, deve-se acrescentar a isso a constatação de Myrian de Oliveira (2004, p. 2), segundo a qual "a cultura religiosa que engendrou o barroco em Minas Gerais foi a mesma que engendrou o rococó, continuando a prevalecer na segunda 
metade do século XVIII o mesmo clima de espiritualidade de fonte contra-reformista, em seus aspectos aparatosos nos rituais do culto católico."

Por esses motivos, grande parte das peças do Museu do Oratório de Ouro Preto, cuja produção é situada no período colonial, apresenta características de ambos os estilos, ora com o predomínio de um, ora de outro, como foi exemplificado anteriormente, evidenciando a possibilidade da coexistência das linguagens estéticas predominantes na época na confecção do mesmo oratório.

As figuras a seguir são apresentadas para reforçar esse argumento e a hipótese de que em oratórios, elaborados durante o período colonial mineiro, expostos no Museu dos Oratórios de Ouro Preto, os seus produtores utilizaram como referência os padrões estéticos dos dois estilos artísticos predominantes no referido período, com um conjunto de características iconográficas composto por elementos de ambos, o que permite concebê-los como exemplo da sensibilidade plástica da época e do modo de satisfazer às demandas das necessidades cotidianas da vida religiosa.

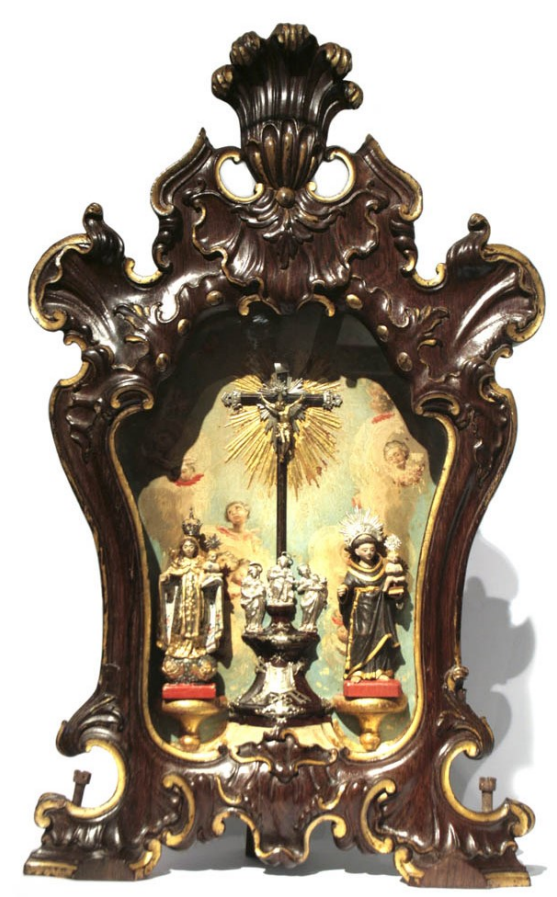

Figura 7. Fonte: Museu do Oratório: imagem MO 218. 


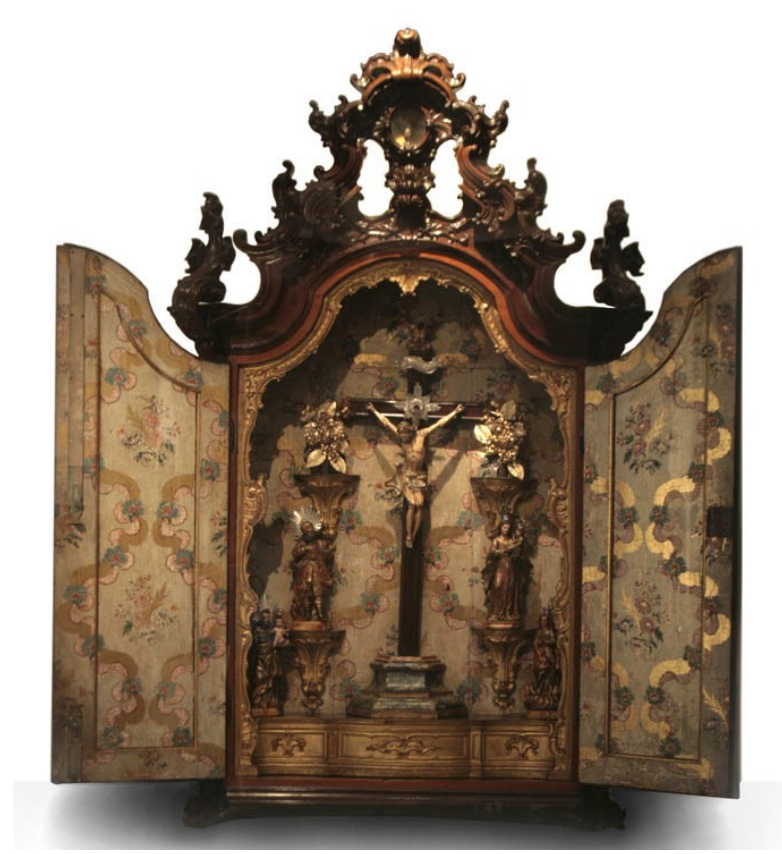

Figura 8. Fonte: Museu do Oratório: imagem MO 168.

Em ambas, notam-se uma ornamentação expressiva, destacadamente no entalhamento profuso no qual se insinuam rocalhas, com volutas acentuadas, cimalha arrematada por ornamentação conchoidal e uma estrutura retabular composta, mais na primeira delas, por curvas irregulares, indefinidas que quebram a robustez do período joanino.

Na primeira, a pintura é composta por anjos, em atitude contemplativa, suspensos entre nuvens claras e dispersas em um céu azul claro, que confere uma leveza, uma certa harmonia, no conjunto cênico com o qual está integrada, evidenciando o crucifixo. Dessa maneira, embora a cenografia seja barroca, tanto no tema, quanto na composição pictórica e escultural que formam o interior do retábulo (expressando a religiosidade de uma sociedade muito apegada aos ideais contrarreformistas), a estrutura retabular é elaborada a partir da nova cultura estética, com destaque para o entalhamento profuso, que nascia, no período josefino, com os pálidos reflexos do Iluminismo francês.

$\mathrm{Na}$ segunda, também iconograficamente elaborada conforme a linguagem rococó, tanto na estrutura, quanto na ornamentação, a pintura, sobre um fundo madrepérola, com motivos florais recobre todo interior do artefato conferindo a ele uma ornamentação que denota o carácter bucólico marcante da linguagem rococó, mas para enfatizar um tema característico do estilo barroco: o drama da crucificação que evoca a angustiante preocupação com a vida espiritual e o seu anseio pela salvação.

\section{A persistência de uma tradição}

Os oratórios ainda são muito populares no Brasil e também em Portugal de onde eles foram trazidos para cá. Em Minas Gerais, particularmente nas cidades pertencentes ao seu antigo circuito colonial, como a de Ouro Preto, onde muitas tradições religiosas originárias da colonização continuam sendo ainda praticadas, sua produção mantém-se alta para satisfazer demandas devocionais e decorativas.

A sua permanência em épocas que transcendem o seu período histórico original não quer dizer que a religiosidade por eles simbolizada seja a mesma de outrora. Isso porque, o exercício da fé, apesar de fazer parte de um costume de longa duração e de conservar alguns elementos ritualísticos de um passado distante, sofre a influência implacável das transformações estruturais pelas quais uma sociedade passa durante sua experiência, devido aos resultados da dinâmica das relações dialéticas que as impulsionam. 
Todavia, em relação aos seus aspectos formais, após o período estudado neste artigo, o Barroco e, principalmente, o Rococó foram persistentemente cultivados, até pelo menos meados do século XIX, como referência estilística hegemônica da cultura estética configurada nos centros urbanos onde tais estilos alcançaram um elevado nível de excelência reconhecido internacionalmente, inclusive pela UNESCO.

No Museu do Oratório, há conservadas diversas peças desse extraordinário mobiliário religioso, produzidas tanto no referido século quanto no seguinte, que testemunham a continuidade de uma rica tradição cultural herdada do tempo da colônia, como as figuras apresentadas na sequência comprovam.

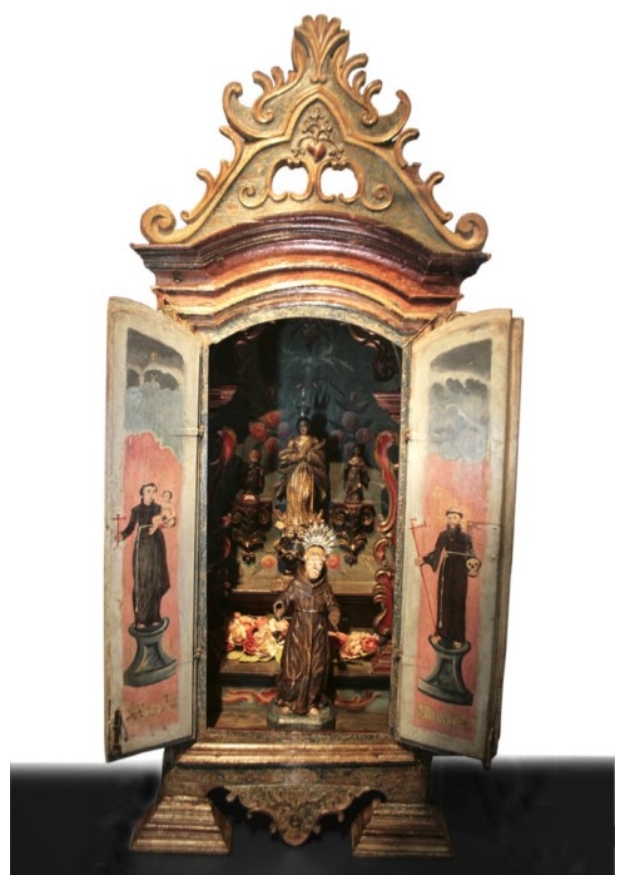

Figura 9. Fonte: Museu do Oratório: imagem MO 200.

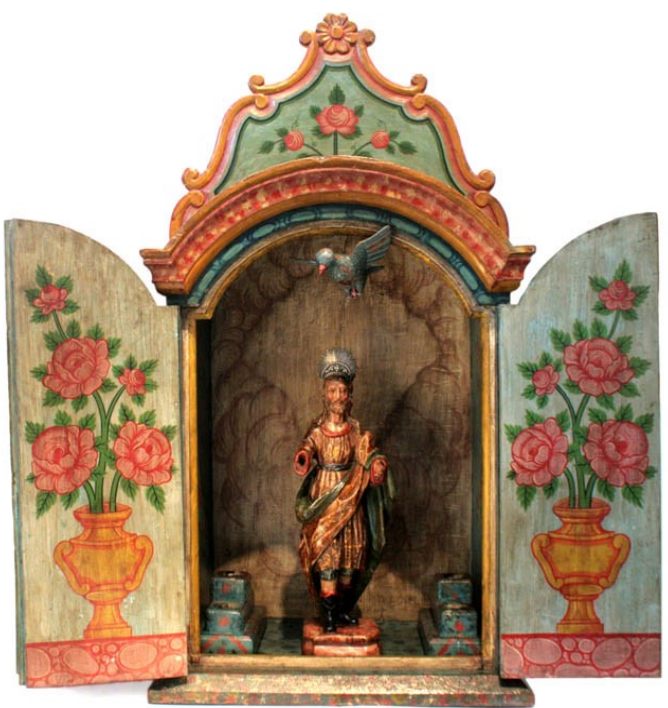

Figura 10. Fonte: Museu do Oratório: imagem MO 136. 


\section{Considerações finais}

Os oratórios analisados nesta pesquisa, como um artefato construído para exercer função devocional, revelam que os seus artífices participaram da dinâmica sintonia criativa da cultura estética, do qual assimilaram um conjunto de valores, do tempo e lugar em que atuaram, expressando, consequentemente, os estilos Barroco e Rococó então predominantes.

Ao expressar tais linguagens artísticas, eles apresentam traços e elementos iconográficos de ambas, ora com predominância de uma, ora de outra, o que permite identifica-los como exemplos do ecletismo característico de parte considerável da produção em Portugal e, por extensão, em partes do seu vasto império, como na Capitania de Minas Gerais, onde um conjunto de fatores, tais como a cultura religiosa, o vigor econômico, a sensibilidade estética, a oferta de artesãos habilidosos, etc. criou as condições para que a sociedade que ali se organizou experimentasse uma extraordinária intensidade criativa, que os oratórios também testemunham.

Dessa maneira, embora tivessem sido produzidos para a satisfação funcionais das demandas religiosas da época (e assim valorizados no tempo da sua produção apenas pelo seu valor de uso), não se pode negar que muitos deles podem ser interpretados como objetos dotados de valor artístico (em retrospectiva, com base nas convenções consagradas durante o longo período que nos separam deles) de uma sociedade cujas marcas mais profundas, e ainda reluzentes, estão dispersas em diversos lugares de memória, alguns deles tomados pela UNESCO, onde ainda podemos contemplá-las como património cultural da humanidade.

\section{Referências}

ARIÈS, Philippe. Por uma história da vida privada. Ed. Chartier, Roger (Org.), 7-19, A história da vida privada. São Paulo: Cia das Letras, 1989, p. 7-19.

ÁVILA, Affonso. O lúdico e as projeções do mundo barroco. São Paulo: Perspectiva, 1994.

BORGES, Nelson Correia. História da arte em Portugal: do barroco ao rococó. Lisboa: Alfa, 1987.

BOURDIEU, Pierre. Os usos sociais da ciência. São Paulo: Ed. Unesp, 2004.

. Bourdieu, Pierre. A economia das trocas simbólicas. $5^{\mathrm{a}}$ ed., São Paulo: Perspectiva, 2001.

BRANDÃO, Angela. Revista CPC, s/1, n. 9, p. 42-64, nov. 2009/abr. 2010.

BRANDÃO, Ângela. Das pontes aos castiçais: a produção de mobiliário artístico em Minas Gerais do século XVIII e os ofícios mecânicos. In: Revista Científica, s/1, v. 4, n. 2, p. 50-66, 2009.

COELHO, Beatriz Ramos de Vasconcelos (org.). Devoção e Arte imaginária religiosa em Minas Gerais. São Paulo, Edusp, 2005.

CALADO, Margarida. Barroco do norte, barroco do sul: algumas reflexões. In: Carlos Alberto Ferreira de Almeida: In memoriam. Porto: Faculdade de Letras, vol. 1, pp. 201-209, 1999.

COULANGES, Fustel de. A cidade antiga. São Paulo: Martins Fontes, 2004.

ECO, Umberto. Obra aberta. São Paulo: Perspectiva, 1971.

ESPINHA, Rodrigo Baeta. Teoria do Barroco. Salvador: Ed. Edufba, 2012.

FERRERES, Juan B. Los oratorios y el altar portátil... 2ª ed., Barcelona: Administración de Razón y fé, 1916.

GEERTZ, Clifford. A Interpretação das culturas. Rio de janeiro: Jorge Zahar, 1978.

GOMES, Paulo Varela. A cultura arquitectónica e artística em Portugal no século XVIII. Lisboa: Caminho, 1988. 
GRAMMONT, Guiomar de. Aleijadinho e o aeroplano: o paraíso barroco e a construção do herói colonial. Rio de Janeiro: Civilização Brasileira, 2008.

GUSDORF, Georges. Dieu, la nature, l’homme au siécle des lumiéres. Paris: Payot, 1972.

HAZARD, Paul. A crise da consciência europeia: 1680 - 1715. Rio de Janeiro: Ed. UFRJ, 2015

. O pensamento europeu no século XVIII. Lisboa: Editorial Presença, 1973.

HAUSER, Arnold. História social da arte e da literatura. São Paulo: Martins Fontes, 2000.

O conceito de Barroco. Lisboa: Vega, 1997.

HELMUT, Hatzfeld. Estudios sobre el Barroco. Madrid: Editorial Gredos, 1966.

KIMBALL, Fiske. Le Style Louis XV: origine et évolution du rococó. Paris, A. et J. Picard, 1949.

LAUFER, Roger. Style rococo, style des Lumières. Paris: J. Corti, 1963.

LEBRUN, François Obra: As Reformas: Devoções comunitárias e piedade pessoal. Ed. Chartier, Roger (Org.), , A história da vida privada. São Paulo: Cia das Letras, 76 -112, 1989.

MAINSTONE, Madeleine e Rowland. O Barroco e o século XVII. São Paulo: Círculo do Livro, 1980.

MARAVALL, José Antonio. A cultura do Barroco. Análise de uma estrutura histórica. Tradução: Silvana Garcia. São Paulo: Edusp, 1997.

MATA, Sérgio da. Chão de Deus - Catolicismo popular, espaço e proto-urbanização em Minas Gerais, Brasil. Séculos XVIII-XIX. Berlin: Verlarg, 2002.

MINGUET, Philippe. Esthétique du rococó. Paris: Librairie Philosophique J. Vrin, 1966, 2édition, 1979.

GUTIERREZ, Angela. Museu do Oratório. Belo Horizonte: Instituto Cultural Flávio Gutierrez, 1999.

OLIVEIRA, Maristane Carvalho. Laços de fé: os oratórios mineiros do século XVIII. Belo Horizonte: Monografia, Centro universitário de Belo Horizonte, 2009

OLIVEIRA, Myriam Andrade Ribeiro de e Campos, Adalgisa Arantes. Barroco e Rococó nas igrejas de Ouro Preto e Mariana. Brasília: DF: Iphan / Programa Monumenta, 2010, v 1.

. Situação contemporânea dos estudos da arquitetura e artes visuais em Minas Gerais no século XVIII. Belo Horizonte: Anais do XXIV Colóquio do CBHA, 2004.

. O Rococó religioso no Brasil e seus antecedentes europeus. São Paulo: Cosac \& Naify, 2003.

PIMENTEL, António Felipe. Os grandes empreendimentos joaninos. In: TEIXEIRA, José de Monterroso et al. O triunfo do Barroco. Belém: Cento Fundação das descobertas/Cultural de Belém, 1993 p. 31-37.

PANOFSKY, Erwin. O significado nas artes visuais. São Paulo: Perspectiva, 2001. Reginaldo, Felipe Camargo et al. A origem do culto aos santos: um olhar historiográfico, Caderno Intersaberes, v. 7, n. 12, 63-84, 2018.

RODRIGUES, Lucas (a). Oratórios domésticos: devoção e arte em Minas Gerais. www.museuregionaldesãojoaodelrey.org.br. Acessado em 29/07/2020.

. (b) 'Decorar para indicar' - A ornamentação Rococó nos oratórios domésticos devocionais como elemento de indicação iconográfica: Portugal e Minas Gerais - séculos XVIII-XIX. Rocalha Revista eletrônica do Centro de Estudos e Pesquisas em História da Arte e Patrimônio da UFSJ, São João Del Rey, v. 1, 352-373, 2020.

ROQUE, Maria Isabel Rocha. Altar Cristão. Evolução até à Reforma Católica. Lisboa: Universidade Lusíada, 2004. 
RUSSO, Silveli Maria de Toledo. Espaço doméstico, devoção e arte: A construção histórica do acervo de oratórios brasileiro - séculos XVIII e XIX. São Paulo: Alameda, 2014.

SANTOS, Reynaldo dos. História da arte em Portugal. V. 3, Porto: editora Portucalense, 1953.

SMITH, Robert. Igrejas, casas e móveis. Aspectos da arte colonial brasileira. Recife: Universidade Federal de Pernambuco, 1979.

SOUZA, Laura de Mello. O diabo e Terra de Santa Cruz. São Paulo: Cia das Letras, 1989.

TEIXEIRA, José de Monterroso. O triunfo do Barroco. In: TEIXEIRA, José de Monterroso et al. $O$ triunfo do Barroco. Belém: Cento Fundação das descobertas/Cultural de Belém,1993, introdução.

THOMAS, Catherine . Les Petits romantiques et le rococo: éloge du mauvais goût. Romantisme, S/L, n. 123, 21- 39, 2004.

VAL, Andréa Vanessa da Costa e Rosário, Rayane Soares. O Barroco e Rococó Mineiro: arte, arquitetura, artistas. Jurisp. Mineira, Belo Horizonte, a. 63, n. 203, 13-22, 2012.

VERDON, Jean. Être chrétien au Moyen Âge. Paris: Perrin, 2018.

VILLARI, Rosario. O homem barroco. Lisboa: Editorial Presença, 1995.

WÖLFFLIN, Heinrich. Renascença e Barroco. São Paulo: Perspectiva, 2012.

. Conceitos Fundamentais da História da Arte. São Paulo: Martins Fontes, 1982. 